\title{
Pengaruh Latihan Push Up Terhadap Prestasi Tolak Peluru Pada Siswa Kelas II SMA Negeri 11 Blang Cut Tahun Pelajaran 2020/2021
}

\author{
Yudi Ikhwani \\ Email : yudiikhwanimpo@gmail.com
}

\begin{abstract}
Abstrak
Penelitian ini berjudul "Pengaruh Latihan Push Up terhadap Prestasi Tolak Peluru pada Siswa Kelas II SMA Negeri 11 Blang Cut Tahun Pelajaran 2020/2021" Permasalahannya seberapa besar pengaruh latihan push up dapat meningkatkan prestasi nomor tolak peluru. Tujuan penelitian ini adalah untuk mengetahui pengaruh latihan push up terhadap prestasi tolak peluru pada Siswa Kelas II SMA Negeri 11 Blang Cut Tahun Pelajaran 2020/2021. Populasi dalam penelitian ini adalah seluruh Siswa Kelas II SMA Negeri 11 Blang Cut Tahun Pelajaran 2020/2021, yang berjumlah 250 orang. Sedangkan sampel penelitian ditetapkan sebanyak $15 \%$ dari total populasi, berjumlah 37 orang. Teknik pengambilan sampel adalah purporsive random sampling atau sampel bertujuan. Teknik pengumpulan data dilakukan melalui pengukuran lapangan dengan menggunakan alat tes kemampuan tolak peluru. Data yang diperoleh dianalisis dengan teknik uji t pada taraf signifikansi 95\%. Hasil analisis data diperoleh nilai t-hitung $=$ 6,85 , lebih besar dari nilai t-tabel pada taraf signifikansi $95 \%=2,02$.Dengan demikian dapat disimpulkan bahwa Terdapat pengaruh yang signifikan latihan push-up terhadap prestasi tolak peluru pada Siswa Kelas II SMA Negeri 11 Blang Cut Tahun Pelajaran 2020/2021.
\end{abstract}

\section{Kata Kunci : Push Up Terhadap Prestasi Tolak Peluru}

\section{PENDAHULUAN}

Sumber daya manusia yang baik, khususnya atlet yang merupakan objek pembinaan olahraga harus dibina secara terus menerus baik fisik, mental maupun emosionalnya agar siap menghadapi dan mengikuti suatu pertandingan dan melahirkan prestasi yang dapat mengharumkan nama bangsa dan negara. Pembinaan kondisi fisik dapat dilakukan melalui latihan-latihan yang teratur, terprogram dan sistematis, serta sesuai dengan cabang olahraga yang dilatih. Hal ini dikarnakan tidak semua cabang olahraga menuntut kemampuan fisik yang sama. Demikian juga dengan cabang olahraga atletik, pembinaan kemampuan fisik harus dibedakan antara satu nomor perlombaan dengan nomor perlombaan lainnya.

Cabang olahraga atletik khususnya nomor tolak peluru, kemampuan fisik atlet memegang peranan yang sangat penting bagi setiap dalam usaha memperoleh prestasi. Komponen-komponen fisik dimaksud adalah kecepatan, kekuatan, dan tenaga. Oleh karena itu peningkatan dan pengembangan kekuatan sangat penting agar mampu menyelesaikan setiap beban fisik yang berat tanpa mengalami kesukaran yang berarti. Dalam hal ini Soemosardjuno (1990:53) mengemukakan bahwa : "Melempar dan mengayun memerlukan tenaga badan bagian atas. Kekuatan yang hebat dan otot-otot yang besar memberikan penekanan pada program latihan beban pada para atlet tolak peluru, lempar cakram, lontar martil dan lempar lembing".

Program latihan peningkatan kekuatan harus dilaksanakan dan diperhatikan dengan sebaik-baiknya. Tidaklah banyak waktu bagi pelempar khususnya nomor tolak peluru untuk memikirkan sistem umpan balik dalam mengatur gerak. Dengan kata lain 
kapasitas penolak peluru akhirnya ditentukan oleh kekuatan, kecepatan, tenaga, dan teknik. Dalam hal ini Soemosardjuno (1990:60) menambahkan bahwa : "Empat komponen pokok dalam melempar yaitu kekuatan, kecepatan, tenaga dan teknik. Menyatukan komponen tersebut merupakan langkah terakhir dalam mengembangkan latihan yang efektif". Hubungan ketiga komponen tersebut hanya dapat ditingkatkan dengan latihan jangka panjang yang bertujuan memperbaiki ketiga komponen tersebut.

Tolak peluru yang merupakan salah satu nomor lempar dalam cabang olahraga atletik, dalam mencapai prestasinya sangat ditentukan oleh kekuatan dan daya tahan otot lengan. Karena kualitas kekuatan merupakan faktor yang paling utama yang harus dimiliki oleh seorang atlet khususnya atlet tolak peluru. Kekuatan di dalam nomor lempar ini tertuju pada peningkatan kemampuan bagian bahu, otot lengan yang merupakan bagian yang sangat dominan dipergunakan. Sejalan dengan hal tersebut Baley (1986:13) mengatakan bahwa: "Semakin besar kekuatan, tenaga, ketahanan, kelincahan serta kelenturan yang dimiliki semakin cepat keterampilan khusus (spesific skill) dikuasai, maka semakin sempurna performancenya".

Untuk memperoleh kekuatan yang maksimal, telah banyak ditemukan bentukbentuk latihan peningkatan kekuatan oleh para pakar olahraga. Salah satu bentuk latihan peningkatan kekuatan otot lengan dan bahu adalah gerakan pus up. Harsono (1988:130) menjelaskan bahwa: "Peningkatan kekuatan dapat dilakukan dengan bentuk latihan push up dengan frekwensi 3 kali seminggu, repetisi 20 kali perset, dan durasi latihan 30 menit selama 6 sampai dengan 8 minggu".

Uraian di atas, menjelaskan bahwa latihan push up dapat meningkatkan komponen kekuatan otot, khususnya kekuatan otot lengan dan bahu. Namun demikian masih perlu dipertanyakan kembali apakah memang benar latihan push up dapat meningkatkan prestasi nomor tolak peluru. Untuk menjawab rumusan masalah tersebut sangat perlu dilakukan suatu pembuktian empiris melalui sebuah penelitian.

Objek penelitian ini adalah siswa SMA, dengan pertimbangan bahwa siswasiswa SMA pada dasarnya sudah menguasai teknik tolak peluru yang baik, karena sebagaimana termuat dalam kurikulum SMA materi tolak peluru dipelajari pada caturwulan III kelas I. Pertimbangan lain adalah bahwa sebagian besar dari siswa SMA belum terkontaminasi dengan latihan-latihan peningkatan kekuatan otot lengan dan bahu, sehingga hasil penelitian diharapkan akan lebih baik. SMA tersebut adalah SMA Negeri 11 Blang Cut Tahun Pelajaran 2020/2021.

Berdasarkan uraian-uraian di atas, penulis berkeinginan mengadakan suatu penelitian dan menetapkan judul : "Pengaruh Latihan Push $\boldsymbol{U}$ p terhadap Prestasi Tolak Peluru pada Siswa Kelas II SMA Negeri 11 Blang Cut Tahun Pelajaran 2020/2021".

\section{Tujuan Penelitian}

Sesuai dengan permasalahan yang telah dirumuskan di atas maka penulis menetapkan tujuan penelitian ini sebagi berikut : "Untuk mengetahui pengaruh latihan push up terhadap prestasi tolak peluru pada siswa Kelas II SMA Negeri 11 Blang Cut Tahun Pelajaran 2020/2021".

\section{KAJIAN TEORITIS}

\section{Pengertian Latihan Push $\boldsymbol{U p}$}

Menurut Bompa (1994:14) mengatakan bahwa: "Latihan merupakan proses yang sistematis atau bekerja secara berulang-ulang dalam jangka waktu panjang, yang ditingkatkan secara bertahap secara individual yang ditujukan pada pembentukan 
fungsi fisiologis dan psikologis untuk memenuhi tuntutan tugas". Sedangkan Harsono (1988:27) memberi pengertian Latihan : "Proses yang sistematis dari berlatih atau bekerja secara berulang-ulang yang kian hari kian bertambah jumlah beban latihan atau pekerjaannya". Latihan yang dilakukan secara sistematis melalui pengulangan (repetition) yang semakin meningkat memberi pengaruh yang baik terhadap mekanisme saraf. Gerakan-gerakan otomatis dan reflektif semakin kurang membutuhkan konsentrasi pusat-pusat saraf dibandingkan sebelum latihan. Latihan yang dilakukan berulang-ulang tanpa meningkatkan beban, kurang ada manfaatnya. Pengaruh dari beban berlebih (overload) menyebabkan peningkatan kemampuan cardiovasculer (jantung dan peredaran darah) dan otot rangka dapat terus berkembang.

\section{Teknik Dasar Tolak Peluru}

Usaha yang tidak mengenal lelah untuk memperbaiki teknik tolakan, terutama terarah pada memperbaiki lintas percepatan yang lebih lurus dan membuat lintas gerak percepatan yang lebih panjang, dengan harapan agar kecepatan lepas alat yang ditolak menjadi lebih tinggi. Hal ini dapat dilihat pada perubahan-perubahan sikap awalan penolak peluru, namun semua variasi teknik harus mempertimbangkan serta memperhitungkan hukum biomekanik, yang merupakan faktor-faktor terpenting yang menentukan prestasi pada tolak peluru. Hal ini sebagaimana dikemukakan Jonath (1988:44) sebagai berikut:

- Lintasan percepatan pelurunya

- Tinggi berangkat dan sudut pelurunya.

- Putaran antara poros bahu dan poros pinggang.

- Percepatan peluru pada waktu mulai ditolak.

- Pengakhiran semua tolakan tenaga bagian secara bersama dan pada saat yang tepat, dan terutama kordinasi antara gerakan lengan dan kaki.

\section{Pengaruh Latihan Push up terhadap Prestasi Tolak Peluru}

Sebagaimana telah dijelaskan bahwa kekuatan otot lengan dan bahu merupakan unsur yang sangat berperan dalam peningkatan prestasi tolak peluru, maka pengembangan latihan kekuatan dalam tolak peluru sangat perlu diperhatikan dan direncanakan dengan baik. Salah satu jenis latihan yang dapat dilakukan adalah gerakan push up. Hal ini disebabkan selama latihan push up otot-otot pada gelang bahu (shoulder girdle) dan persendian siku terjadi interaksi. Adapun otot-otot tersebut seperti deltoides dan pectoralis major, dimana otot tersebut berada di bagian depan bahu dan atas serta otot besar yang menutupi bagian depan dada dan yang melekat pada klavikula (Soemosardjuno,1990:43).

Lebih lanjut Soemosardjuno (1990:43) menjelaskan bahwa: "Olahraga push up memang banyak manfaatnya, antara lain untuk mengembangkan otot-otot dada, bahu dan lengan. Dengan demikian jelaslah bahwa apabila gerakan push up dilakukan dengan baik dan benar serta sesuai dengan prinsip-prinsip latihan akan dapat meningkatkan kekuatan otot lengan dan bahu yang merupakan indikator tercapainya prestasi tolak peluru secara optimal.

\section{METODE PENELITIAN \\ Jenis Penelitian}

Penelitian ini temasuk ke dalam jenis penelitian eksperiment yaitu penelitian yang bermaksud mengetahui pengaruh suatu perlakuan atau latihan terhadap variabel tertentu. Dimana kepada subjek akan dilakukan tes awal, kemudian diberikan perlakuan 
selama 6 minggu dan selanjutnya akan dilakukan tes akhir. Dalam hal ini, pengaruh latihan push up terhadap prestasi tolak peluru.

\section{Waktu dan Tempat Penelitian}

Penelitian ini dilaksanakan selama enam minggu, dimulai dari tanggal 10 Februari 2021 sampai dengan selesai, bertempat di SMA Negeri 11 Blang Cut Banda Aceh.

\section{Rancangan Penelitian}

Penelitian ini bersifat pengukuran lapangan. Untuk mendapatkan data yang baik dalam penelitian ini, memerlukan suatu rancangan atau gambaran tentang pelaksanaan penelitian. Rancangan penelitian merupakan suatu rencana, struktur dan strategi yang harus dikuasai seorang peneliti untuk menjawab permasalahan yang akan dihadapi.

\section{Populasi dan Sampel Penelitian}

Populasi adalah keseluruhan dari subjek penelitian yang akan diteliti atau diselidiki. Sesuai dengan judul penelitian ini, maka yang menjadi populasi dalam penelitian ini adalah seluruh siswa putera Kelas II SMA Negeri 11 Blang Cut Tahun Pelajaran 2020/2021, yang berjumlah 250 orang. Sampel dalam penelitian ini siswa kelas II SMA Negeri 11 Blang Cut Tahun Pelajaran 2020/2021, untuk lebih jelasnya dapat dilihat pada tabel 1 berikut ini.

Tabel Jumlah Populasi dan Sampel Penelitian Siswa Kelas II SMA Negeri 11 Blang Cut Tahun Pelajaran 2020/2021

\begin{tabular}{|c|l|l|l|l|}
\hline No. & Kelas & Populasi & Sampel 15\% & Keterangan \\
\hline 1. & $\mathrm{II}_{1}$ & 19 & 3 & Sampel \\
2. & $\mathrm{II}_{2}$ & 23 & 4 & diambil \\
3. & $\mathrm{II}_{3}$ & 22 & 3 & adalah \\
4. & $\mathrm{II}_{4}$ & 26 & 4 & urutan 1, 2 \\
5. & $\mathrm{II}_{5}$ & 23 & 3 & dan 3 terbaik \\
6. & $\mathrm{II}_{6}$ & 24 & 4 & perkelas \\
7. & $\mathrm{II}_{7}$ & 25 & 4 & \\
8. & $\mathrm{II}_{8}$ & 21 & 3 & \\
9. & $\mathrm{II}_{9}$ & 20 & 3 & \\
10. & $\mathrm{II}_{10}$ & 21 & 4 & \\
11. & $\mathrm{II}_{1}$ & 23 & 37 & \\
\hline & Jumlah & 250 & 3 & \\
\hline
\end{tabular}

Sumber: Tata Usaha SMA Negeri 11 Blang Cut Tahun Pelajaran 2020/2021.

\section{Teknik Pengumpulan Data}

Untuk mendapatkan data dalam penelitian ini, langkah-langkah yang harus ditempuh adalah pre-test dan post test.

\section{Teknik Pengolahan Data}

Untuk membuktikan hipotesis yang telah dirumuskan serta untuk menjawab permasalahan yang timbul dalam penelitian ini, maka semua data yang diperoleh dianalisis dengan statistik, yaitu formula t-tes pada taraf signifikansi $95 \%$ atau $\propto=$ 0,05 . 


\section{Hasil Penelitian}

Dari keseluruhan jumlah populasi yang ada, yang diambil sebagai sampel penelitian ini hanya 37 orang siswa. Rangkaian pelaksanaan pengumpulan data penelitian pengaruh latihan push up terhadap prestasi tolak peluru pada SMA Negeri 11 Blang Cut Tahun Pelajaran 2020/2021, telah diperoleh data penelitian. Untuk memudahkan pengolahan data, selanjutnya data tersebut ditabulasikan ke dalam tabeltabel berikut ini.

\section{Hasil Tes Awal}

Hasil tes awal prestasi tolak peluru SMA Negeri 11 Blang Cut Tahun Pelajaran 2020/2021, diperoleh data penelitian sebagai terdapat dalam tabel di bawah ini.

Tabel Hasil Tes Awal Prestasi Tolak Peluru SMA Negeri 11 Blang Cut Tahun Pelajaran 2020/2021

\begin{tabular}{|c|c|c|c|}
\hline No & Nama & Hasil Tes $\left(\mathrm{X}_{1}\right)$ Meter & $\mathbf{X}_{1}{ }^{2}$ \\
\hline 1. & Adam Khadafi & 7,80 & 60,84 \\
\hline 2. & Aris Akbar & 6,50 & 42,25 \\
\hline 3. & Agus Tia Pratama & 6,30 & 39,69 \\
\hline 4. & Fazlu Fazariannur & 5,50 & 30,25 \\
\hline 5. & Fitrian Putra & 5,30 & 28,09 \\
\hline 6. & Habibie Maulana & 6,90 & 47,61 \\
\hline 7. & Imam Fahrum & 6,40 & 40,96 \\
\hline 8. & Iqram & 4,70 & 22,09 \\
\hline 9. & Isnan Maulidi & 5,30 & 28,09 \\
\hline 10. & Khairil Ikbal & 6,20 & 38,44 \\
\hline 11. & M. Alif Al Khaidar & 5,80 & 33,64 \\
\hline 12. & M. Hijrah & 5,80 & 33,64 \\
\hline 13. & M. Zulmi & 5,90 & 34,81 \\
\hline 14. & Mahfud & 6,20 & 38,44 \\
\hline 15. & Majar Ramadhana & 5,60 & 31,36 \\
\hline 16. & Malik Rizal & 6,60 & 43,56 \\
\hline 17. & M. Aris Munandar & 6,50 & 42,25 \\
\hline 18. & M. Ikbal & 5,80 & 33,64 \\
\hline 19. & Nawal Askan & 5,80 & 33,64 \\
\hline 20. & Rahmady & 5,00 & 25,00 \\
\hline 21. & Randa Aulia & 6,30 & 39,69 \\
\hline 22. & Reza Maulana & 4,90 & 24,01 \\
\hline 23. & Riskan Armis & 7,00 & 49,00 \\
\hline 24. & Teuku Fathur & 5,70 & 32,49 \\
\hline 25. & Teuku Maulana Daffa & 6,20 & 38,44 \\
\hline 26. & Zulfikri & 5,80 & 33,64 \\
\hline 27. & Zuvar Zidan & 5,70 & 32,49 \\
\hline 28. & Imam Khalik & 5,50 & 30,25 \\
\hline 29. & Khairuman Andika & 4,70 & 22,09 \\
\hline 30. & M. Ardiansyah & 6,60 & 43,56 \\
\hline 31. & M. Reza & 5,60 & 31,36 \\
\hline 32. & Aprianda & 5,30 & 28,09 \\
\hline 33. & M. Riski khalik K & 3,80 & 14,44 \\
\hline 34. & T. Ilham Dzikrullah & 6,70 & 44,89 \\
\hline 35. & M. Firdaus & 6,30 & 39,69 \\
\hline 36. & T. Riski Saputra & 5,25 & 27,56 \\
\hline
\end{tabular}




\begin{tabular}{|c|l|c|c|}
\hline 37. & M. Rafli Akbar & 7,20 & 51,84 \\
\hline & Jumlah & $\mathbf{2 1 8 , 4 5}$ & $\mathbf{1 3 1 1 , 8 2}$ \\
\hline
\end{tabular}

\section{Hasil Tes Akhir}

Hasil tes akhir merupakan sasaran dari penelitian ini, dimana hasilnya akan dibandingkan dengan data tes awal untuk melihat sejauh mana program latihan yang dijalankan berpengaruh terhadap prestasi tolak peluru. Tes akhir dilakukan setelah sampel menjalankan program latihan selama 6 minggu. Hasil tes akhir diperoleh data penelitian sebagaimana terdapat dalam table.

Tabel Hasil Tes Akhir Prestasi Tolak Peluru SMA Negeri 11 Blang Cut Tahun

Pelajaran 2020/2021

\begin{tabular}{|l|l|l|l|}
\hline No & Nama & Hasil Tes $\left(\mathbf{X}_{2}\right)$ Meter & $\mathbf{X}_{\mathbf{1}}^{\mathbf{2}}$ \\
\hline 1. & Adam Khadafi & 7,90 & 62,41 \\
2. & Aris Akbar & 8,50 & 72,25 \\
3. & Agus Tia Pratama & 7,90 & 62,41 \\
4. & Fazli Fazariannur & 7,50 & 56,25 \\
5. & Fitrian Putra & 6,60 & 43,56 \\
6. & Habibie Maulana & 7,70 & 59,29 \\
7. & Irsyanuddin & 7,50 & 56,25 \\
8. & Imam Fahrum & 4,95 & 24,50 \\
9. & Iqram & 6,50 & 42,25 \\
10. & Isnan Maulidi & 6,60 & 43,56 \\
11. & Khairil Ikbal & 7,70 & 59,29 \\
12. & M. Alif Al Khaidar & 6,40 & 40,96 \\
13. & M. Hijrah & 7,60 & 57,76 \\
14. & M. Alfi & 8,30 & 68,89 \\
15. & M. Zulmi & 7,20 & 51,84 \\
16. & Mahfud & 7,50 & 56,25 \\
17. & Majar Ramadhana & 8,10 & 65,61 \\
18. & Malik Rizal & 6,20 & 38,44 \\
19. & M. Aris Munandar & 6,70 & 44,89 \\
20. & M. Ikbal & 6,30 & 39,69 \\
21. & Nawal Askan & 7,40 & 54,76 \\
22. & Rahmady & 46,24 \\
23. & Randa Aulia & 6,80 & 60,84 \\
24. & Reza Maulana & 7,80 & 47,61 \\
25. & Riskan Armis & 6,90 & 45,56 \\
26. & Teuku Fathur & 6,75 & 51,84 \\
27. & Teuku Maulana Daffa & 7,20 & 42,25 \\
28. & Zulfikri & 6,50 & 42,25 \\
29. & Zuvar Zidan & 39,69 \\
30. & Imam Khalik & 6,50 & 62,41 \\
31. & Khairuman Andika & 6,30 & 42,90 \\
32. & M. Ardiansyah & 7,90 & 51,84 \\
33. & M. Reza & 6,55 & 26,01 \\
34. & Aprianda & 7,20 & 54,76 \\
35. & M. Riski khalik K & 5,10 & 45,69 \\
36. & T. Ilham Dzikrullah & 7,40 & \\
37. & M. Firdaus & 6,70 & \\
& & 8,70 & \\
\hline
\end{tabular}




\begin{tabular}{|l|l|l|}
\hline Jumlah & $\mathbf{2 6 3 , 8 5}$ & $\mathbf{1 9 0 8 , 9 4}$ \\
\hline
\end{tabular}

\section{Pembahasan Hasil Penelitian}

Penelitian ini hanya dijalankan selama 6 minggu, jadi besarnya kemungkinan terjadi kekurangan-kekurangan terhadap pencapaian hasil maksimal. Disamping itu, penulis tidak mengasramakan sampel, sehingga sulit bagi penulis untuk melakukan pengontrolan terhadap kegiatan lain yang dilakukan sampel sehari-hari, jam istrirahat dan juga mental sampel. Namun penelitian ini telah dilakukan dan secara statistik program latihan push up yang penulis berikan kepada sampel memberikan pengaruh yang signifikan terhadap prestasi tolak peluru.

Penelitian ini dilakukan hanya sebatas pembuktian teori-teori yang telah dikemukakan para ahli olahraga, namun demikian penelitian ini diharapkan dapat menjadi bahan masukan yang berarti bagi pengembangan ilmu pengetahuan secara umum dan lebih khusus lagi pengembangan ilmu keolahragaan dalam rangka peningkatan prestasi cabang olahraga atletik nomor tolak peluru.

Pengembangan kekuatan otot lengan melalui jenis latihan push up yang dijalankan secara terprogram, dengan beban yang semakin hari semakin meningkat telah memberi bukti nyata dapat meningkatkan prestasi tolak peluru. Harre yang disadur Soemosardjuno (1990:47) menjelaskan bahwa: "Latihan yang dijalankan selama 6-14 minggu dengan frekwensi latihan 3-5 kali seminggu sudah cukup berarti bagi peningkatan kekuatan otot". Latihan yang dijalankan hendaknya disesuaikan dengan prinsip-prinsip latihan, dan tujuan yang diharapkan.

\section{Kesimpulan}

Dari hasil penelitian, pengolahan serta analisis data, maka dapat diambil beberapa kesimpulan sebagai berikut: Jenis latihan push up memberikan pengaruh yang baik terhadap peningkatan prestasi tolak peluru pada siswa SMA Negeri 11 Blang Cut Tahun Pelajaran 2020/2021.

\section{DAFTAR PUSTAKA}

Arikunto. Suharsimi, (1997), Prosedur Penelitian Suatu Pendekatan Praktis, PT. Rineka Cipta, Jakarta. , (1991), Prosedur Penelitian Suatu Pendekatan Praktis, PT. Rineka Cipta, Jakarta.

Baley, J.A. (1986), Pedoman Atlet, Cetakan Pertama, Dahara Prize: Semarang.

Bompa. TO, (1994), Theory and Methodology of Training, 1st-Ed, Kendell/Hunt Publishing Company: Lowa.

Harsono, (1988), Coaching dan Aspek-aspek Psikologis dalam Coaching. Departemen Pendidikan dan Kebudayaan: Jakarta.

Jonath, U. (1988), Atletik, PT. Roda Jaya Putra: Jakarta.

Soemosardjuno, Sadoso. (1990). Pengetahuan Praktis Kesehatan dalam Olahraga. PT. Gramedia: Jakarta. 